\title{
Cancer burden in Africa in 2030: Invest today and save tomorrow
}

\section{Le fardeau du cancer en Afrique d'ici 2030 : investir aujourd'hui pour sauver demain}

\author{
B. S. Sylla $\cdot$ C. P. Wild \\ C Springer-Verlag France 2012
}

Long mistakenly thought of as a disease predominantly of developed countries, cancer is now recognized as a global concern that does not respect geographical, economic, ethnic or social barriers. Cancer remains one of the principal causes of adult mortality worldwide, and is increasingly considered a major public health problem. Although significant progress has been made in recent years in understanding the molecular basis of the disease and developing therapies and appropriate prevention strategies, cancer incidence and mortality continue to increase. In 2008 an estimated 12.7 million new cancer cases and 7.6 million deaths occurred worldwide [1]. Even more striking, the International Agency for Research on Cancer (IARC) anticipates a near-doubling of the annual number of new cases and deaths in 2030, as the sole result of population growth and ageing [1]. Remarkably, the IARC projections indicate that this increase will fall most heavily on developing countries; currently $56 \%$ of new cases and $64 \%$ of cancer deaths occur in less-developed countries, while in just 20 years' time the figures will be $63 \%$ and $70 \%$ respectively [2].

Unfortunately, Africa remains poorly prepared to cope with the cancer endemic. Approximately 715000 new cancer cases, including 542000 deaths, were estimated to have occurred in Africa in 2008. In 2030, assuming no changes in current underlying incidence rates, these figures will rise to 1.3 million new cases and just under 1 million deaths [2]. For the sake of comparison, the estimated death toll caused in 2008 by HIV/AIDS infection in Sub-Saharan Africa was 1.4 million [3]. This staggering increase in cancer cases and its inherent consequences will only extend the delay suffered by Africa in its economic and social development. If the exposure to cancer risk factors such as tobacco, chronic infections and some aspects of a Westernized lifestyle becomes more prevalent, then these figures would represent under-estimates.

\section{B. S. Sylla $\cdot$ C. P. Wild $(\bowtie)$}

International Agency for Research on Cancer,

150 Cours Albert-Thomas, 69372 Lyon Cedex 08, France

e-mail : director@iarc.fr
It should be noted that approximately $25-30 \%$ of all cancers in Africa are caused by or associated with infections $[4,5]$. Prominent among these are infections with human papillomaviruses in the development of cervical cancer, the hepatitis B and C viruses in liver cancer, Helicobacter pylori in gastric cancer, Kaposi sarcoma-associated herpes virus in Kaposi sarcoma, and Schistosoma haematobium in bladder cancer $[4,5]$.

African political authorities, health professionals and civil society must combine efforts, in close collaboration with international organizations, to develop an effective strategy to fight cancer. This approach must necessarily include education and information to raise the profile of cancer in Africa and promote a focus on cancer prevention, and the establishment of adequate facilities for early detection and treatment of patients (including palliative care). These developments must be in association with improved coverage and quality of cancer registration to ensure that governments can plan adequately for the challenges ahead and evaluate the benefits of interventions. The provision of training and the development of cancer research programs are also vital if these African problems are eventually to be answered by the African cancer community itself. With resources being limited, the unifying role of African institutions such as the African Organization for Research and Training in Cancer (AORTIC) remains important to the success of regional initiatives which should involve co-operation across national boundaries.

Cancers of the breast, cervix, liver, prostate and esophagus, along with lymphomas, are among the most common cancers in Africa (Fig. 1). As most cancers in Africa are diagnosed at a late stage and access to cancer therapies is limited, upstream interventions are an essential response. Measures should include, for example, the early detection and treatment of precancerous lesions of the cervix as well as introduction of vaccination against HPV; the international community must also press for the provision of affordable HPV vaccine. Vaccination against the hepatitis B virus (HBV) is a high priority for the prevention of liver cancer, as are clean needles, avoidance of unnecessary injections, and screening of blood transfusions for HBV and HCV. There may be future opportunities to broaden access to 


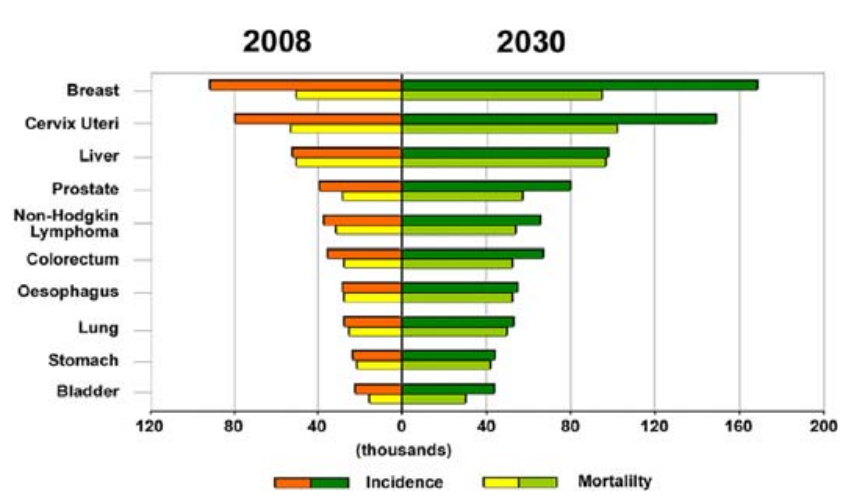

Fig. 1 The growing cancer burden in Africa: estimated numbers of new cases and deaths in 2008 and 2030, both sexes combined. Note that this chart does not include Kaposi sarcoma

treatment for those chronically infected with HBV using antiviral drugs. Early detection of breast cancer, possibly by greater breast cancer awareness and clinical breast examination, may offer viable alternatives to mammography screening. The fight against tobacco use through legislation and other controls, including implementation of the World Health Organization Framework Convention on Tobacco Control (WHO FCTC), must remain a priority. Increasing physical activity and avoiding obesity among the population will further prevent breast cancers, colon and endometrium. In addition, adequate clinical resources such as radiation therapy, chemotherapeutic drugs (generics) and palliative care are all important measures in the fight against cancer in Africa. Ultimately, promoting and institutionalizing cancer research in Africa, as well as training researchers and clinicians, will contribute to the response to this global epidemic.

All these measures would have little or no effect if they were not part of a long-term approach through national cancer control programmes, integrated into the structures of the public health policy of African countries. In this respect the high-level United Nations summit on noncommunicable diseases (NCD) held in New York in September 2011 offered an exceptional opportunity to ensure that the international NCD agenda will meet the priorities of Africa. Whilst risk factors common in many high-income countries, such as tobacco, alcohol, healthy diet and physical inactivity, are relevant to Africa and are becoming more so, a focus on these alone will be an inadequate response. Notably, the need to combat the major contribution of chronic infections as risk factors (notably through vaccinations against HBV and, as the price falls, HPV) and to prioritize the early detection and treatment of cervical and breast cancers is vital. To omit these areas would be to fail Africa at a critical point for NCD control across the continent. African politicians and decision-makers have a remarkable opportunity to translate into action the adopted declaration of the NCD high level meeting in New-York for the benfit of their populations.

Acknowledgments : We thank Jacques Ferlay for his help in preparing this article.

\section{References}

1. http://www.who.int/healthinfo/global_burden_disease/GBD_report_ 2004update_AnnexA.pdf

2. Ferlay J, Shin H-R, Bray F, et al (2010) GLOBOCAN 2008: Cancer incidence and mortality worldwide, IARC CancerBase No. 10 [Internet]. Lyon, France. Available from: http://globocan.iarc.fr

3. http://data.unaids.org/pub/Report/2009/JC1700 Epi_Update_2009_en.pdf

4. Parkin DM, Sitas F, Chirenje M, et al (2008) Part I: Cancer in indigenous Africans - burden, distribution, and trends. Lancet Oncol., 9:683-692

5. Sitas F, Parkin DM, Chirenje M, et al (2008) Part II: Cancer in indigenous Africans - causes and control. Lancet Oncol., 9:786-795 